\title{
Scientific collaboratories in higher education: exploring learning style preferences and perceptions of technology
}

\section{Diane H. Sonnenwald and Bin Li}

Diane H. Sonnenwald is an Associate Professor and Bin Li is a doctoral candidate at the School of Information and Library Science at the University of North Carolina, USA. Address for correspondence: Diane Sonnenwald, University of North Carolina, CB \#3360, Chapel Hill, NC 27599-3360 USA. Tel: +1 919962 8065; fax: +1919962 8071; email: dhs@ils.unc.edu

\begin{abstract}
Scientific collaboratories hold the promise of providing students access to specialized scientific instruments, data and experts, enabling learning opportunities perhaps otherwise not available. However, evaluation of scientific collaboratories in higher education has lagged behind their development. We conducted a repeated-measures study that provided data regarding social interaction learning styles and perceptions of a scientific collaboratory system from 40 university science students working face-to-face and remotely. Students with a strong competitive learning style preference or who worked with a student with a strong competitive learning style reported a slightly more positive perception of the relative advantage, compatibility and complexity of the collaboratory system. Students with a strong individualistic learning style preference or who worked with a student with a strong individualistic learning style reported a more negative perception of the observability of the system. No relationships were found between students' cooperative learning style preference and their perceptions of the system after using it face-to-face or remotely.
\end{abstract}

\section{Introduction}

Scientific collaboratory systems hold the promise of providing students at many academic levels access to specialized scientific instruments, data and experts using information and communications technology, including the Internet. They potentially enable authentic learning opportunities otherwise not available. However, evaluation of scientific collaboratories in higher education has lagged behind their development. There is a need to increase our understanding of scientific collaboratories in the context of higher education. For example, we do not know if scientific collaboratories inherently benefit some students while placing others at a disadvantage. To explore this issue,

(C) British Educational Communications and Technology Agency, 2003.

Published by Blackwell Publishing Ltd., 9600 Garsington Road, Oxford OX4 2DQ, UK and 350 Main Street, Malden, MA 02148, USA. 
we conducted an evaluation of a scientific collaboratory system using learning style and innovation adoption theory to investigate students' perceptions of the system.

\section{Theoretical framework}

Learning style theory suggests that individuals have different ways of learning, and when teaching accommodates these styles, learning is enhanced. Learning styles can be based on different preferences in cognitive information processing (eg, Kolb, 1984), personality or temperament (eg, Keirsey, 1998), and social interaction (eg, Owens and Straton, 1980; Grasha, 1996). Because collaboratories obviously change social interaction by replacing face-to-face interaction with computer-mediated interaction, and because research has shown that social interaction impacts learning (eg, Barron, 2000), our research focuses on learning styles based on social interaction preferences.

Research investigating learning styles based on social interaction preferences has identified three preferences: cooperative, competitive and individualistic (Owens and Straton, 1980). A cooperative preference characterizes students who favour working conjointly with peers. A competitive preference characterizes students who enjoy competing with others, and an individualistic preference characterizes students who prefer having no involvement with others when learning.

These categories have been widely used to investigate academic achievement of students from different populations and in different countries. For example, studies have investigated academic achievement and cooperative, competitive and individualistic learning styles among undergraduate students (Van-Voohris, 1991; Van-Voorhis, 1995; Emanuel and Potter, 1992), primary and secondary students (Owens and Straton, 1980; Owens and Barnes, 1982; Okebukola, 1986; Owens, 1992), AfricanAmerican adolescents (Johnson and Engelhard, 1992; Johnson, 1993), and senior high gifted students (Li and Adamson, 1992, 1995; Nelson, 1996). These studies have also been conducted in a variety of countries including Canada (Li and Adamson, 1995), Australia, England and USA (Owens, 1992), and in Australia, New Zealand, England and USA (Owens, Nolan, and McKinnon, 1992). Results generally indicate that academic achievement is often predicted by competitive and individualistic preferences. However, cooperative learning activities appear to be superior in promoting academic achievement for all students.

As previously mentioned, collaboratories change social interaction by replacing faceto-face interaction with computer-mediated interaction. In computer-mediated communication, multiple and redundant communication channels, implicit cues, spatial co-references and social context cues are constrained by technology (Olson and Olson, 2000). This may impair interaction, and ultimately learning, because it is more difficult to establish the common ground and social context that enables individuals to understand the meaning of each other's utterances. For example, showing a partner new ideas represented by a diagram spontaneously sketched on a piece of paper is easy to do when face-to-face. It may require multiple actions, such as putting the diagram into an electronic format and sharing the results using specialized network applica- 
tions, when collaborating across distances. We do not know how students with different social interaction learning styles perceive collaboratory systems that impose these types of differences. Therefore, we explored the following hypothesis: Students' perceptions of the scientific collaboratory system will be influenced by their social interaction learning style preferences.

\section{Research method}

To investigate relationships among students' competitive, individualistic and cooperative learning styles and their perceptions of a scientific collaboratory system, we conducted a repeated measures experiment comparing working face-to-face and working remotely with the order of conditions counterbalanced. Twenty pairs of students conducted two scientific research labs each requiring 2 to 3 hours to complete. Students completed a lab collaborating face-to-face on one occasion and, on a different day, collaborating remotely (in different locations). When face-to-face, the students shared a single collaboratory system; when collaborating remotely, each location was equipped with a complete collaboratory system.

The nanoManipulator collaboratory

The scientific collaboratory system used in this study provides distributed, collaborative access to a specialized scientific instrument called a nanoManipulator (nM). An nM provides haptic and 3D visualization interfaces to an atomic force microscope, providing a scientist with the ability to interact directly with physical samples ranging in size from DNA to single cells (Taylor II and Superfine, 1999).

The collaboratory system (Sonnenwald et al, 2001) is comprised of two PCs. One PC provides haptic and 3D visualization interfaces to a local or remote atomic force microscope and supports collaborative manipulation and exploration of scientific data collected from the microscope. It also allows scientists to dynamically switch between working together in shared mode and working independently in private mode. In shared mode, collaborators view and analyze the same (scientific) data. In private mode, each collaborator can independently analyze the same or different data previously generated. Mutual awareness is supported via multiple pointers, each showing the focus of attention and interaction state for one collaborator. Collaborators are able to perform most operations synchronously.

The second PC provides shared application functionality, video conferencing and an electronic drawing tablet. This allows collaborators to work together synchronously using a variety of software applications, including specialized data analysis, word processing and whiteboard applications. Two cameras support video conferencing. A wireless telephone connected to a commercial telephone network provides high quality audio communications for collaborators.

\section{Study participants}

The study participants were third and fourth year university natural science students from doctoral/research universities. The science and math skills of this population are 
somewhat consistent, as they must take a core set of science and math courses during their first two years at the universities. Students were recruited through various advertisements and received $\$ 100$ for their participation (less than $\$ 10.00$, or $£ 6.4$, per hour).

The majority of the students were majoring in biology (23); others were majoring in chemistry (6), physics (5), biochemistry (4), and biomaterial science (2). Thirty-six students were Caucasian, 2 were African American and 2 were Asian/Indian. All were fluent in English and all but one appeared to be a native English speaker. Students were randomly assigned to pairs without respect to their major, self-reported grade point average and ethnicity. We strove for a mix of gender composition in the pairs; 9 pairs were of mixed gender, 6 pairs were female only and 5 pairs were male only. Twenty-five percent of the students (5 pairs out of 20) knew their partner before participating in the experiment, a situation that mirrors educational practice. Due to the small number of previously acquainted pairs in our study, it was not possible to determine if the previous acquaintance statistically affected the results. To avoid bias or confounding results, no student had experience conducting scientific research labs across distances or using the nanoManipulator. In addition, no student had any substantive knowledge of fibrin, the biological material under investigation in the experiment. Because this study was part of a larger study with different research goals, we were unable to assign students to pairs based on their learning style preferences. While this mirrors typical practice in real life educational settings, it restricts the conclusions that can be drawn from this study.

\section{Experimental design}

The experiment consisted of three sessions: an Introduction, Lab Session 1, and Lab Session 2. These sessions were iteratively refined in a pilot study that included 6 different participants.

The introduction consisted of a presentation providing background information on the controlled experiment, an introduction to the natural science used in the experiment, and a hands-on demonstration of the collaboratory system. During the introduction students completed a learning style preference questionnaire. In most cases paired participants attended the introductory session together, however, in a few cases this was not possible.

Lab sessions 1 and 2 were performed on different days and under different conditions: face-to-face and remote. The order of the conditions was counterbalanced. Pairs were randomly assigned to the two order conditions. The lab sessions took place within a one-week timeframe. Each session had three parts: a tutorial, science lab and a post-questionnaire.

The hands-on tutorial led participants through instructions on how to use the features of the collaboratory system required for that day's lab. Each participant completed the 
tutorial individually and was accompanied by a researcher/observer who was available to answer questions. Participants were allowed to spend as much time as they wanted on the tutorial; typically they spent 45 minutes.

Both science labs were designed in collaboration with natural scientists who regularly teach and use the nanoManipulator. The labs were based on actual activities the scientists completed and documented during the course of their investigations, and were designed to be similar to labs in third and fourth year university courses. The topic of the labs was the structure of fibrin, the substance that is responsible for clotting blood. Both labs were designed to be similar in difficulty as judged by the natural scientists and pilot study participants. To complete the labs the students had to engage in the following activities typical of natural science research and education in laboratory settings: operate the scientific equipment properly; capture and record scientific data; analyze data using scientific data analysis software applications; draw conclusions, create hypotheses and support those hypotheses based on their data analysis; and document all work and ideas in an electronic lab notebook, or report (Figure 1). Students were allowed to spend as much time as they wished working on the lab.

After every lab, each student participant was asked to individually complete a post-questionnaire that took approximately 20 minutes to complete. The completed questionnaires provided data regarding students' perceptions of the collaboration system as discussed below.

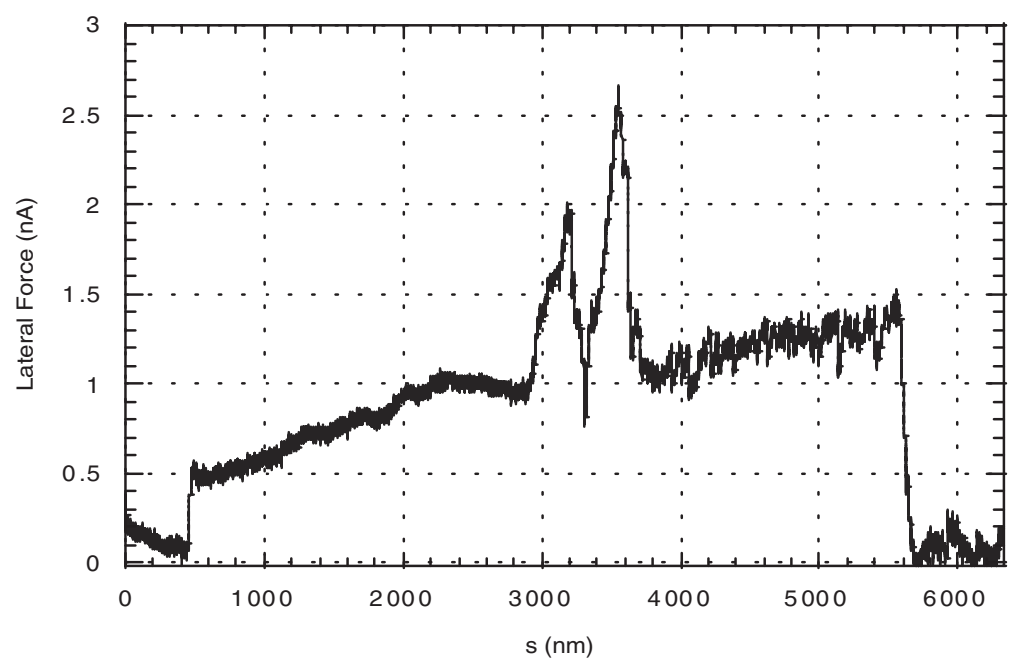

Figure 1: Example lab report page 


\begin{abstract}
Measures
Learning preference styles: LPSS instrument

To determine student participants' learning style preferences, we used the Learning Preference Scale: Students (LPSS) developed by Owens and Straton (1980). This instrument consists of thirty statements regarding preferences with respect to working with peers, competing with peers, and having no involvements with others, indicating cooperative, competitive and individualistic learning preferences. Participants are asked to indicate how true or false each statement is for them on a four-point semantic differential scale with the endpoints labelled "completely false" and "completely true." These responses are summed for each scale, and each participant is assigned three scores, indicating the strength of their preference for each learning style. Each score has a possible value range from 10 to 40. The Cronbach's alpha values calculated using data from our study are $0.76,0.80$ and 0.67 for the cooperative, competitive and individualistic scale, respectively.
\end{abstract}

An alternative categorization of learning styles based on social interaction includes collaborative, competitive, independent, dependent, participant and avoidant preferences (Grasha, 1996). The avoidant style characterizes students who are uninterested and do not participate in the classroom, whereas the participant style characterizes students who are eager to participate. These styles would not be randomly represented in our sample population because all participants were volunteers, and thus would most likely score high on the participant scale and low on the avoidant scale. Therefore, we did not use this categorization.

Perceptions of collaboratory system: Innovation adoption questionnaire Innovation adoption and diffusion theory provides a foundation for investigating students' perceptions of the scientific collaboratory system. Synthesizing over five decades of innovation adoption research, Rogers (1995) identifies five attributes of innovations that are correlated with adoption and use.

Relative advantage is the degree to which potential adopters perceive that an innovation surpasses current practice. Relative advantage can be operationalised as usefulness in accomplishing goals, quality of task outcomes, added convenience and social prestige provided by the innovation.

Compatibility is the degree to which an innovation is perceived to be consistent with adopters' existing values, past experiences and needs. It is concerned with the level of congruence between a person's traditional behaviour and the behaviour required by the innovation.

Complexity refers to the perceived difficulty of learning to use and understand a new system or technology. When a system is perceived as complex, it may inhibit learning. 
Trialability refers to the ease of experimenting with an innovation. It includes the level of effort needed and the risk involved in observing and participating in small-scale demonstrations of the system, including the ease with which you can recover from (or "undo") an action taken using the system.

Observability is the degree to which the results of the innovation are easily seen and understood. We extended the concept of observability and developed questions focusing on observability between collaborators. For example, the question "I learned new ways of using the technology from my partner" investigates the degree to which an individual can observe and learn about the system from his or her partner.

We developed a questionnaire probing students' perceptions of these attributes and administered the questionnaire after both conditions to enable a comparison of results. Details regarding the construction and validation of the questionnaire instrument can be found in Sonnenwald, Maglaughlin and Whitton (2001).

\section{Results}

Students' learning style preferences

Students learning style preferences varied as, ideally, happens with a random sample population (Table 1). A Pearson correlation test to investigate possible correlations between learning styles indicates that only statistically significant correlation among the scores occurs between the cooperative and individualistic scores. This correlation is negative, illustrating the ability of the instrument to differentiate between contrasting learning style preferences.

Using the Pearson correlation test to compare students' competitive, cooperative and individualistic scores with their age, number of university credit hours completed, or major yielded no statistically significant correlation (at the $\rho<=.05$ level).

Table 1: Learning preference scores and correlations for participants $(n=40)$

\begin{tabular}{|c|c|c|c|c|c|c|c|c|c|}
\hline & & & & & & \multicolumn{4}{|c|}{ Correlation Data } \\
\hline & \multicolumn{5}{|c|}{ Descriptive Data } & \multicolumn{2}{|c|}{ Competitive } & \multicolumn{2}{|c|}{ Cooperative } \\
\hline & Mean & Min & $\operatorname{Max}$ & Range & $S D$ & Correlation & $\rho$ & Correlation & $\rho$ \\
\hline Competitive & 24.8 & 14 & 39 & 25 & 4.81 & & & & \\
\hline Cooperative & 30.1 & 19 & 37 & 18 & 4.19 & -0.133 & .413 & & \\
\hline Individualistic & 27.7 & 22 & 36 & 14 & 3.43 & .276 & .085 & -.450 & .004 \\
\hline
\end{tabular}


Relationships among students' learning style preferences and perceptions of the scientific collaboratory system

As discussed previously, all students completed the innovation diffusion questionnaire after each session (Table 2). A previous analysis (Sonnenwald et al, 2003) illustrated there are no statistically significant differences in scores due to condition.

Regression analyses, or repeated measures analysis of variance, were performed to investigate whether differences in the adoption questionnaire responses can be attributed to learning style preferences, or due to any interaction between learning style preferences and condition, ie, face-to-face or remote. The results (Table 3) suggest

Table 2: Post-questionnaire responses for adoption attributes $(n=40)$

\begin{tabular}{|c|c|c|}
\hline \multirow[b]{2}{*}{ Adoption Attribute } & \multicolumn{2}{|c|}{$\begin{array}{c}\text { Mean (SD) } \\
\text { Scale: } 1 \text { (low) to } 5 \text { (high) }\end{array}$} \\
\hline & Face-to-Face & Remote \\
\hline Relative advantage & $4.13(0.60)$ & $4.05(0.72)$ \\
\hline Compatibility & $4.15(0.64)$ & $4.20(0.60)$ \\
\hline Complexity & $1.26(0.62)$ & $1.30(0.75)$ \\
\hline Trialability & $4.10(0.80)$ & $3.89(0.82)$ \\
\hline Observability & $3.42(0.85)$ & $3.50(0.72)$ \\
\hline
\end{tabular}

Table 3: Regression analysis of differences in perceptions of innovation attributes due to learning style preferences

\begin{tabular}{|c|c|c|c|c|c|c|c|c|c|c|}
\hline & \multirow[b]{2}{*}{ Comparison } & \multicolumn{3}{|c|}{ Competitive } & \multicolumn{3}{|c|}{ Cooperative } & \multicolumn{3}{|c|}{ Individualistic } \\
\hline & & $d f$ & $t$ & $\rho$ & $d f$ & $t$ & $\rho$ & $d f$ & $t$ & $\rho$ \\
\hline \multirow{5}{*}{ 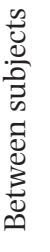 } & Relative advantage & 38 & 2.52 & 0.02 & 38 & 1.08 & 0.29 & 38 & 1.59 & 0.12 \\
\hline & Compatibility & 38 & 2.69 & 0.01 & 38 & 0.49 & 0.62 & 38 & 0.33 & 0.74 \\
\hline & Complexity & 38 & 1.93 & 0.06 & 38 & 1.18 & 0.25 & 38 & 0.00 & 0.99 \\
\hline & Trialability & 38 & 0.14 & 0.89 & 38 & 0.30 & 0.77 & 38 & 0.17 & 0.87 \\
\hline & Observability & 38 & 0.28 & 0.78 & 38 & 0.47 & 0.64 & 38 & 2.00 & 0.05 \\
\hline \multirow{5}{*}{ 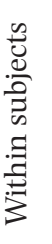 } & Relative advantage & 38 & 0.88 & 0.38 & 38 & 0.72 & 0.47 & 38 & 0.71 & 0.48 \\
\hline & Compatibility & 38 & 1.56 & 0.13 & 38 & 1.24 & 0.22 & 38 & 1.37 & 0.18 \\
\hline & Complexity & 38 & 2.10 & 0.04 & 38 & 1.26 & 0.22 & 38 & 0.00 & 0.99 \\
\hline & Trialability & 38 & 0.58 & 0.56 & 38 & 1.02 & 0.31 & 38 & 1.12 & 0.27 \\
\hline & Observability & 38 & 0.10 & 0.93 & 38 & 1.11 & 0.27 & 38 & 1.26 & 0.22 \\
\hline
\end{tabular}


that, in general, students' preference for the competitive learning style is related to their perceptions of the collaboratory system's relative advantage and compatibility. Furthermore, students' preference for the individualistic learning style influences their perceptions of the collaboratory system's observability. Interestingly, students' preferences for the cooperative learning style show no statistically significant relationships with respect to perceptions of the collaboratory system.

The regression analyses also indicate that a preference for the competitive learning style influences students' perceptions of the collaboratory's complexity, based on condition. That is, when working remotely, students who indicate a preference for the competitive learning style perceive the collaboratory system's complexity lower after using the system remotely than after using the system face-to-face.

Regression analyses investigating relationships between perceptions of the collaboratory system in each condition and learning preferences show that every unit of increase in a student's competitive learning style score is associated with a 0.05 unit increase in students' perceptions of the system's relative advantage when they learn remotely $(\rho=0.02$ ); 0.06 unit increase in students' perceptions of the system's compatibility when they learn remotely $(\rho=0.01)$; and 0.05 unit decrease in students' perceptions of the system's complexity when they learn remotely $(\rho=0.01)$. Similarly, every unit of increase in a student's individualistic score is associated with a 0.08 unit decrease in the student's perception of observability when learning remotely $(\rho=0.01)$.

This implies that every 12.5 to 20 point difference in individualistic and competitive learning style scores will most likely impact students' perceptions of the technology's relative advantage, complexity and observability by one full point on a five-point scale. A spread of 12.5 to 20 points can be expected among any group of students. For example, as shown in Table 1, the ranges of student's individualistic and competitive learning style scores in our sample were 14 and 25 , respectively.

When students learn in small group situations other group members may influence their attitudes and opinions. Our study participants worked in dyads, and thus their shared experiences or discussions about the system may have had an influence on their individual evaluations of the system afterwards. Therefore, we used the SAS Software for the Statistical Analysis of Correlated Data (SUDAAN, version 9.0) designed for the analysis of cluster-correlated data. That is, we analyzed the innovation attribute and learning style preference data taking into account any possible correlations between innovation attribute scores of a group's participants.

The results of the univariate regression analysis (Table 4), which assumes students who work together influence each other's attitudes toward the collaboratory system, yields two new associations that are statistically significant at the $\rho<=.05$ level. These are associations between students' competitive learning style and their perceptions of relative advantage and compatibility in the face-to-face condition. 
Table 4: Univariate regression analysis testing for differences in perceptions due to learning style preferences assuming correlations between group members $(n=40)$

\begin{tabular}{|c|c|c|c|c|c|c|c|c|c|c|}
\hline & \multirow[b]{3}{*}{ Innovation Attribute } & \multicolumn{9}{|c|}{ Learning Style Preference } \\
\hline & & \multicolumn{3}{|c|}{ Competitive } & \multicolumn{3}{|c|}{ Cooperative } & \multicolumn{3}{|c|}{ Individualistic } \\
\hline & & Int. & $\beta$ & $\rho^{*}$ & Int. & $\beta$ & $\rho^{*}$ & Int. & $\beta$ & $\rho^{*}$ \\
\hline \multirow{5}{*}{ 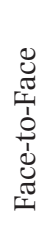 } & Relative Advantage & 3.39 & 0.03 & 0.04 & 5.11 & -0.03 & 0.19 & 2.72 & 0.05 & 0.08 \\
\hline & Compatibility & 3.49 & 0.03 & 0.04 & 4.31 & -0.01 & 0.81 & 3.37 & 0.03 & 0.36 \\
\hline & Complexity & 3.37 & 0.02 & 0.42 & 3.42 & 0.01 & 0.50 & 3.78 & 0.00 & 1.00 \\
\hline & Trialability & 3.83 & 0.01 & 0.65 & 4.79 & -0.02 & 0.49 & 4.78 & -0.03 & 0.58 \\
\hline & Observability & 3.23 & 0.01 & 0.67 & 3.43 & 0.00 & 0.99 & 4.69 & -0.05 & 0.33 \\
\hline \multirow{5}{*}{ 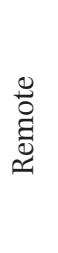 } & Relative Advantage & 2.73 & 0.05 & 0.03 & 4.37 & -0.01 & 0.72 & 3.37 & 0.03 & 0.42 \\
\hline & Compatibility & 2.70 & 0.06 & 0.00 & 3.43 & 0.03 & 0.41 & 4.53 & -0.01 & 0.74 \\
\hline & Complexity & 2.45 & 0.05 & 0.04 & 2.62 & 0.04 & 0.12 & 3.78 & 0.00 & 0.99 \\
\hline & Trialability & 3.98 & 0.00 & 0.88 & 3.70 & 0.01 & 0.87 & 3.52 & 0.01 & 0.70 \\
\hline & Observability & 3.35 & 0.01 & 0.82 & 2.71 & 0.02 & 0.31 & 5.75 & -0.08 & 0.04 \\
\hline
\end{tabular}

* $\rho$ refers to the significant levels of the slope $\beta$.

However, the degree of these associations differ somewhat. Every unit of increase in a student's or his or her partner's competitive learning style score is associated with a 0.03 unit increase in students' perceptions of the system's relative advantage when they learn face-to-face, and a 0.05 increase when they learn remotely. Every unit of increase in a student's or her or his partner's competitive learning style score is associated with a 0.03 unit increase in students' perceptions of the system's compatibility when they learn face-to-face, and a 0.06 increase when they learn remotely.

\section{Limitations}

This study has several limitations. One limitation is sample size; data from additional participants may yield new insights. A second limitation related to the sample was the inability to recruit and match student pairs based on learning preferences. Matching could increase our understanding of interactions between students with various preferences. However, matching may or may not be possible in classroom situations, and thus the random assignment of students to dyads done in this study may provide insight into what might happen in real-life settings. A third limitation focuses on the tasks. Although designed to be similar in complexity, the tasks in session 1 and 2 differed. We do not account for this difference in our analysis. Additional investigation may uncover aspects of the tasks that are inherently impacted by an interaction condition. A fourth limitation focuses on students' motivation because the tasks were not done for a grade. We do not know if students' perceptions would differ if the labs were done as part of a course. 


\section{Discussion}

Only partial support is provided for the hypothesis. Synthesizing the results indicates that students with strong competitive learning style preferences and students working with another student with a strong competitive learning style preference, perceived the collaboratory system slightly more positively after using it remotely with respect to the system's advantages, compatibility with their learning styles, values and needs, and complexity. Students with a stronger individualistic learning style preference, and students working with another student with a strong individualistic learning style preference, reported a more negative perception of the observability of the collaboratory system after collaborating remotely. Due to limitations of this study, these results should be interpreted with caution. However, we offer a potential interpretation based on features of the system.

When learning remotely, students working together do not need to physically share many components of the scientific collaboratory system. For example, in our system only movement of the microscope tip requires explicit sharing between collaborators. This has two implications. One, students can take control of many system components and complete tasks by simply inputting commands more quickly than their partner. Two, when working remotely students have more opportunities to complete tasks in parallel either employing a "divide and conquer" strategy or doing complex tasks synchronously. Thus, perhaps students with competitive learning style preferences perceive the system more positively with respect to relative advantages, compatibility and complexity after using it remotely because it allows them greater control over their work, or task, process.

The results also imply that students with a preference for the individualistic learning style find observing one's partner remotely is problematic. Our collaboratory system, as do others, provides video-conferencing through two camera views. However, this does not match the flexibility, richness or convenience of observation possible in faceto-face situations. Other students with a strong cooperative learning style preference reported a work-around to this problem; they proactively and in detail described their actions to their partner when working remotely. We suspect that individualistic learners who prefer no interaction with others may find this work-around problematic.

We found no statistically significant differences in perceptions of the system based on students' cooperative learning style preferences. It appears that the collaboratory system may support their needs equivalently in both face-to-face and remote conditions, or alternatively, they are able to compensate equally well, in face-to-face small group learning situations and in remote small group learning situations. This finding mirrors other research that found no or minimal differences in learning outcomes and students' perceptions of technology based on cognitive information processing learning styles (eg, Lu, Yu, and Liu, 2003; Carswell, 1997; Terrell, 2002).

The results reported in this paper contribute to our understanding of the role of the scientific collaboratory in higher education. The results potentially indicate that scien- 
tific collaboratories today may be feasible authentic science learning environments, but not equivalent learning environments for all types of learners. Further research is needed to confirm or refute these exploratory results. As educators we do not wish to put students in learning situations that provide inherent disadvantages or advantages to students with a specific learning style preference or, alternatively, we may need to recognize and compensate for the inherent advantages and/or disadvantages through other activities.

\section{Acknowledgments}

Our thanks to: Chris Wiesen for guidance regarding the statistical analysis in this paper; the study participants; Martin Guthold and Richard Superfine for their natural science expertise; Mary Whitton, Kelly Maglaughlin, Ron Bergquist, Atsuko Negishi for their roles in conducting the experiment; the nM development team, including Fred Brooks, Aron Helser, Tom Hudson, Kevin Jeffay, David Marshburn, Don Smith, Russell Taylor; and Bob Losee, Mary Whitton and the anonymous reviewers for their helpful comments on this paper. This research work was funded by the NIH National Center for Research Resources, NCRR 5-P41-RR02170.

\section{References}

Barron B (2000) Achieving coordination in collaborative problem-solving groups Journal of the Learning Sciences 9, 4, 403-436.

Carswell L (1997) Teaching via the Internet: The impact of the Internet as a communication medium on distance learning introductory computing students Proceedings of the Second Conference Integrating Technology into Computer Science Education ACM Press, NY. 1-5.

Emanuel R C and Potter W J (1992) Do students' style preferences differ by grade level, orientation toward college, and academic major? Research in Higher Education 33, 3, 395-414.

Grasha A (1996) Teaching with style Alliance Pittsburgh.

Guthold M, Falvo M R, Matthews W G, Paulson S, Washburn S, Erie D A, Superfine R, Brooks Jr F P and Taylor III R M (2000) Controlled manipulation of molecular samples with the nanoManipulator IEEE/ASME Transactions on Mechatronics 5, 2, 189-198.

Johnson D and Johnson R T (1975) Learning together and alone: co-operation, competitive, or individualization Prentice-Hall Englewood Cliffs.

Johnson C (1993) Influences of gender and academic achievement on learning preferences of middle grade students, Annual Meeting of the Mid South Educational Research Association November 10-12.

Johnson C and Engelhard G (1992) Gender, academic achievement, and preferences for cooperative, competitive, and individualistic learning among African-American adolescents Journal of Psychology 126, 4, 385-392.

Keirsey D (1998) Please understand me II Prometheus Nemesis Book, DelMar CA.

Kolb D (1984) Experiential learning Prentice Hall Englewood Cliffs, NJ.

Li A and Adamson G (1992) Gifted secondary students' preferred learning style: cooperative, competitive, or individualistic? Journal for the Education of the Gifted 16, 1, 46-54.

— (1995) Motivational patterns related to gifted students' learning of mathematics, science and English: an examination of gender differences Journal for the Education of the Gifted 18, 3 , 284-297.

Lu J, Yu C and Liu C (2003) Learning style, learning patterns, and learning performance in a WebCT-based MIS course Information and Management 40, 497-507.

Nelson S (1995) The voices of students in cooperative learning: academically gifted and their classroom peers Unpublished PhD dissertation, University of North Carolina at Chapel Hill.

Olson G and Olson J (2000) Distance matters Human-Computer Interaction 15, 2-3, 139-178. 
Okebukola P (1986) The influence of preferred learning styles on cooperative learning in science Science Education 70, 5, 509-517.

Owens L and Straton R (1980) The development of a co-operative, competitive, and individualistic learning preference scale for students British Journal of Educational Psychology 50, $147-161$.

Owens L (1992) The learning mode preferences of secondary students: a three-country comparison-Australia, England, USA Paper presented at the Annual Meeting of the American Educational Research Association (San Francisco, CA, April 20-24).

Owens L, Nolan C and McKinnon D (1992) A comparison of the learning mode preferences of students in four countries-Australia, New Zealand, England, USA Paper presented at the Annual Conference of the Australian Association for Research in Education.

Owens L and Barnes J (1982) The relationships between cooperative, competitive and individualistic learning preferences and students' perceptions of classroom learning atmosphere American Educational Research Journal 19, 2, 182-200.

- (1992) Learning preference scales: handbook and test master set Australian Council for Education Research Ltd. Melbourne.

Rogers E (1995) Diffusion of innovations The Free Press NY.

Sonnenwald D, Whitton M and Maglaughlin K (2003) Evaluating a scientific collaboratory: results of a controlled experiment ACM Transactions on Computer-Human Interaction 10, 2, $150-176$.

Sonnenwald D, Maglaughlin K and Whitton M (2001) Using innovation diffusion theory to guide collaboration technology evaluation: work in progress IEEE $10^{\text {th }}$ International Workshop on Enabling Technologies: Infrastructure for Collaborative Enterprises IEEE Press NY, 114-119.

Sonnenwald D, Bergquist R, Maglaughlin K, Kupstas-Soo E and Whitton M (2001) Designing to support collaborative scientific research across distances: the nanoManipulator example in $\mathrm{E}$ Churchill, D Snowdon, and A Munro, (eds) Collaborative Virtual Environments Springer Verlag London, 202-224.

Taylor II R and Superfine R (1999) Advanced interfaces to scanning probe microscopes in Handbook of Nanostructured Materials and Nanotechnology Academic Press NY.

Terrell S (2002) The effect of learning style on doctoral course completion in a web-based learning environment The Internet and Higher Education 5, 345-352.

Van-Voorhis J (1991) Instruction in teacher education: a descriptive study of cooperative learning, Paper presented at the International Convention on Cooperative Learning Utrecht, Netherlands, July.

(1995) Implementing cooperative structures to increase motivation and learning in the college classroom, Paper presented at the Lilly Conference on College Teaching (Columbia, SC, June 2-4, 1995). 
Copyright $\odot 2003$ EBSCO Publishing 